\title{
Ética jornalística, desenvolvimento moral e phrônesis: aproximações teóricas $^{1}$
}

\author{
Dairan Paul ${ }^{2}$ \\ Rogério Christofoletti ${ }^{3}$
}

\begin{abstract}
Resumo
$\mathrm{O}$ artigo discute quais são os processos cognitivos e morais implicados nos julgamentos realizados por jornalistas. Considera a contribuição de estudos baseados na psicologia para discutir a formação de esquemas e modelos mentais que auxiliam no processamento de informação por parte dos profissionais. Em seguida, apresenta dados sobre pesquisas de desenvolvimento moral que mensuram graus de raciocínio ético. O texto finaliza aprofundando o conceito de phrônesis, considerado como elemento central nos julgamentos de jornalistas. Entende que a empatia, uma das virtudes vinculadas à doutrina aristotélica, permite complexificar a tomada de decisões perante dilemas morais, pois parte de uma perspectiva intersubjetiva e relacional.
\end{abstract}

\section{Palavras-chave}

ética jornalística; desenvolvimento moral; phrônesis

\begin{abstract}
Abstrat
The article discusses the cognitive and moral processes involved in judgments made by journalists. It considers the contribution of psychology-based studies to discuss schemes and mental models that assists professionals in information process. It then presents data on moral development research that measures degrees of ethical reasoning. The article concludes by developing the concept of phronesis, considered as a central element in decision-making process. It understands that empathy, one of the virtues linked to the aristotelian doctrine, allows complex decision-making when facing moral dilemmas, as part of an intersubjective and relational perspective.
\end{abstract}

\section{Keywords}

journalism ethics; moral development; phronesis

1 Este artigo atualiza uma comunicação apresentada no $42^{\circ}$ Congresso Brasileiro de Ciências da Comunicação (Intercom), na Universidade Federal do Pará, em Belém.

2 Doutorando no Programa de Pós-Graduação em Jornalismo da Universidade Federal de Santa Catarina. dairanpaul@gmail.com

3 Doutor em Ciências da Comunicação pela Universidade de São Paulo.

rogeriochristofoletti@gmail.com 


\section{Introdução: uma abordagem multidisciplinar para os estudos em ética jornalística}

$\mathrm{Na}$ falta de um corpo teórico específico, a dimensão moral do jornalismo tende a ser estudada por abordagens quase exclusivamente filosóficas (LORENZO, 2011). Este artigo parte de um esforço de diálogo entre o terreno da ética jornalística - fundamentada, aqui, pela ética das virtudes, em Aristóteles - e os aportes psicológicos da cognição e do desenvolvimento moral. A partir de uma perspectiva multidisciplinar, pretende-se essas contribuições ao conceito de aristotélicos de saber prático (phrônesis), entendido elemento central nos processos de reflexão realizados por jornalistas.

A tomada de decisão, enquanto objeto de estudo, costuma ser abordada em pesquisas dedicadas aos processos produtivos do jornalismo. Tais abordagens sociológicas utilizam a observação de rotinas nas redações como método. Seus resultados desvelam fatores estruturais que condicionam o julgamento de jornalista, bem como o atravessamento de ideologias, instituições, linhas editoriais e valores-notícia (TUCHMAN, 1978; FISHMAN, 1990; GANS, 2004).

Embora reconheça a importância desses estudos, Van Dijk (1990) entende que tais pesquisas não dão conta de explicar os processos cognitivos de interação e produção da notícia. Neste rol, estão inclusas as tomadas de decisão realizadas por jornalistas, o que perpassa também julgamentos de valor acerca daquilo que é certo ou errado. Daí a sugestão do autor para que os estudos microssociológicos adicionem um componente psicológico em suas análises sociais, indo além dos fatores estruturais.

Segundo Donsbach (2004), abordagens psicológicas não são bem recebidas no campo das ciências sociais porque buscam encontrar "leis" no comportamento humano, focando antes nas semelhanças dos indivíduos do que na sua diversidade. No entanto, esta seria uma leitura equivocada: na psicologia, padrões de comportamento não são entendidos como limitações para o comportamento humano.

Stocking e Gross (1999) também advogam por essa defesa, lembrando que pesquisas sobre psicologia cognitiva estiveram, em um primeiro momento, orientadas para os efeitos da comunicação no público. Se na abordagem da recepção partia-se do princípio de que consumidores não eram passivos - ou seja, de que há um processo cognitivo que transforma informação em conhecimento -, o mesmo não acontecia nos produtores: presumia-se que jornalistas eram muito mais afetados por constrangimentos e rotinas organizacionais, de modo que suas atitudes, crenças e valores subjetivos têm pouca ou quase nenhuma contribuição no processo de formação das notícias. Sem desconsiderar a natureza social da prática jornalística, Stocking e Gross (1999) também chamam atenção para os processos cognitivos de conhecimento acionados pelo indivíduo jornalista. 


\section{VOZES $_{\text {\&IÁLORO }}^{\mid}$}

Itajaí, v. 18, n. 02, jul/dez 2019

\section{Processos cognitivos nas tomadas de decisão}

Os processos de deliberação moral realizados por profissionais são sustentados, dentre outros fatores, por uma teoria geral das crenças. Estas são unidades de informação armazenadas em uma das dimensões da mente, a memória, sendo construídas, reativadas e processadas por meio de tarefas cognitivas que resultam em interações e ações sociais. Na abordagem sociodiscursiva de Van Dijk (1998), elas também são consequências de discursos, conceito central para o autor.

Uma vez que a memória também armazena competências e conhecimentos mais abstratos, como andar e comer, faz-se necessária uma delimitação inicial. Crenças são expressas em proposições, estão relacionadas a um conteúdo e são compartilhadas socialmente, formando nossas opiniões sociais. Têm como base um conhecimento cultural e uma ordem moral, fundamentando valores que balizam princípios de julgamentos.

Van Dijk (1990, p. 157) define como "formas especiais de cognição social" as opiniões, atitudes e ideologias, pois pressupõem uma incorporação e compartilhamento de normas e valores em grupos sociais organizados por classe, gênero, faixa etária e etnia, por exemplo. Desse modo, um ato de preconceito é uma ação apenas individual ou “acidental” - pode ser entendido como uma estratégia em sincronia com as necessidades e interesses de grupos que desejam manter uma posição dominante.

Se opiniões sociais são crenças valorativas ligadas à ordem moral da sociedade, o conhecimento, por sua vez, refere-se à ordem epistêmica que fundamenta crenças factuais socialmente compartilhadas. Ele está parcialmente organizado em formas pré-consolidadas que representam o conhecimento estereotipado acerca de ações e acontecimentos da vida social, acionado por meio de modelos mentais. Estes têm a forma de scripts ou esquemas socialmente compartilhados e, quando reunidos, formam algo que vagamente pode-se denominar como "conhecimento de mundo" (VAN DIJK, 2005). Tal conhecimento armazenado de forma esquemática é próximo daquilo que Lippmann (2009) entende por "estereótipos", ou seja, preconcepções que "governam profundamente todo o processo de percepção” (LIPPMANN, 2009, p. 91) e atravessam julgamentos na forma de marcos sociais. Estereótipos são o cerne dos códigos morais de diversos tipos (familiares, profissionais, econômicos, pessoais), chegando ao ponto que "determinam largamente que grupo dos fatos nós veremos, e sob que luz nós os enxergamos” (LIPPMANN, 2009, p. 120).

De forma geral, supõe-se que os processos de avaliação de acontecimentos são regidos por um sistema de valores próprios do jornalismo. Ou seja, se o evento está adequado aos critérios informativos, há mais possibilidades para que ele se transforme em um acontecimento jornalístico. Van Dijk (1990) considera que essa explicação é vaga, pois não explicita "como" ocorre esse processo. 


\section{VOZES $_{\text {\&IÁLORO }}^{\mid}$}

Itajaí, v. 18, n. 02, jul/dez 2019

Para o autor, a percepção e interpretação de acontecimentos resulta de um modelo que é subjetivo, mas socialmente controlado pela memória do repórter. Essa explicação poderia ser dada para quaisquer observações - no caso daquela realizada por um jornalista há objetivos específicos, como a representação do acontecimento tendo em vista seu potencial de reprodução no discurso jornalístico. Categorias cognitivas que definem esse filtro implicam conceitos como interesse público, novidade, consequências etc. Também estão condicionados por fatores estruturais, sendo tempo o mais notório deles. Nesse sentido, a organização das rotinas jornalísticas é feita de modo a compensar certas limitações, como a divisão temática em editorias. Busca-se atender ao maior número possível de critérios, no limite espaço-temporal dado aos profissionais.

Quando se deparam com um grande número de informações, jornalistas utilizam estratégias cognitivas para processá-las. Selecionam fontes credíveis, normalmente ligadas a instituições, e reproduzem (parcial ou integralmente) materiais de assessorias e agências. Donsbach (2004) sintetiza que há certo consenso sobre pelo menos quatro fatores que impactam nas decisões de profissionais a respeito de quais histórias podem ser noticiadas: valores-notícia, objetivos institucionais, poder manipulativo das fontes de notícia e crenças subjetivas dos jornalistas. No entanto, o pesquisador adiciona duas variáveis que podem explicar com mais profundidade esse processo psicológico: a necessidade de uma validação social das percepções, e a condição das pré-disposições já existentes.

Jornalistas tomam decisões factuais e valorativas o tempo inteiro acerca do que é verdadeiro, relevante, bom ou ruim. No entanto, ao contrário de outras profissões, há quatro implicações específicas nas suas tomadas de decisão: elas ocorrem sob pressão de tempo, sob pressão de competição, não possuem critérios objetivos para avalia-las e seus resultados se tornam públicos com mais visibilidade, seja na forma de sucesso ou falha. É por isso que Donsbach (2004) infere que jornalistas vivem "situações indeterminadas", pois seu julgamento de valor ancora-se em alguma medida à realidade e são mais difíceis de serem falseados. O mais próximo que podemos chegar à validação de crenças ou atitudes dos profissionais seria a constituição de realidades compartilhadas. Ou seja, percepções de jornalistas tendem a ser confiáveis quando reproduzidas por outros ${ }^{4}$ e são validadas porque se tornam crenças intersubjetivas - trata-se do fator de validação social.

O segundo aspecto psicológico que influenciaria na percepção de jornalistas é o conjunto de suas pré-disposições ativadas quando se deparam com acontecimentos,

\footnotetext{
${ }^{4}$ No caso do jornalismo, os "outros" são os próprios jornalistas, tanto pelo fácil acesso quanto por representarem normas profissionais e, portanto, serem percebidos como influências legítimas nas tomadas de decisão. Evidentemente, colegas de trabalho não são as únicas referências: Donsbach (2004) lembra que o processo sociopsicológico no julgamento desses profissionais também é atravessado por pressões editoriais, ameaças, censuras e medo de demissão, de modo que a autopercepção que jornalistas têm de si como sujeitos independentes nas suas decisões tende a internalizar uma "conformidade" às rotinas organizacionais. Schmitz (2018) comprova esse argumento ao colher e analisar dados empíricos sobre a discrepância na autonomia que jornalistas brasileiros percebem que têm, e naquela que de fato exercem durante a construção de seus textos.
} 


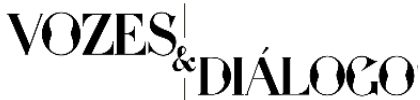

Itajaí, v. 18, n. 02, jul/dez 2019

processam por meio de sistemas cognitivos e os reproduzem. Isso está ligado ao que Donsbach (2004) chama de atenção seletiva (quais estímulos serão respondidos), percepção seletiva (através de quais hipóteses as informações serão processadas) e retenção seletiva (quais informações serão mantidas na memória do jornalista). As pré-disposições afetam jornalistas quando suas opiniões corroboram ou não com o valor-notícia de uma história controversa - semelhante ao que Lippmann (2009) já destacava, ao inferir que tendemos a rejeitar experiências que contrariem nossos estereótipos.

Estes dois fatores psicológicos - a validação social dos julgamentos através de interações, e a estabilização de pré-disposições cognitivas - descrevem comportamentos humanos gerais. Contudo, Donsbach (2004) argumenta que eles estão mais presentes no jornalismo e têm mais relevância para essa prática. São mais recorrentes porque jornalistas, ao contrário de outras profissões, estão constantemente tomando decisões perceptivas acerca de fatos. São importantes porque tais julgamentos formam o ponto de partida de percepção de realidade dos cidadãos, uma vez que nossa imagem de mundo provém também, em alguma medida, dos processos internos que dinamizam as práticas dos jornalistas e geram o conhecimento jornalístico.

\section{O desenvolvimento moral de jornalistas}

Se processos cognitivos são formados por um terreno cultural comum entre os sujeitos, é razoável concluirmos que as tomadas de decisão no jornalismo não podem ser reduzidas apenas a uma reflexão individual. Quando se depara com um dilema, o profissional recorre a valores que fazem parte de uma cultura jornalística. Portanto, enquanto agente moral que compartilham de um ethos específico, jornalistas estão sujeitos à uma dupla condição ética (CHRISTOFOLETTI, 2008): mobilizam valores individuais e sociais; pessoais e deontológicos. Guerra (2001, p. 48-49, grifo do autor) explicita a implicação dialética entre objetividade e subjetividade nas tomadas de decisão:

\begin{abstract}
A partir do momento que o indivíduo é membro de uma comunidade, seu julgamento ético ou sua crítica normativa não é jamais pessoal - o que ele acha que seja uma atitude correta em determinada situação - mas o que a sua comunidade, portanto ele também como membro dela, prescreve como uma boa conduta. Ou seja, a autonomia do indivíduo é restrita ao destino que ele quer para a sua própria vida. Na medida que ele decide fazer ou não parte de uma comunidade moral, ele passa a arcar com as consequências do seu 'querer'. No caso de um indivíduo que opte por não fazer parte, restam-lhe os lances estratégicos e a formalidade das normas, por exemplo.
\end{abstract}

Antes de passarmos às pesquisas sobre tomadas de decisão no jornalismo, cabe um breve resgate histórico sobre esse campo de estudo em sua origem, na psicologia. A linha que pesquisa desenvolvimento moral é fundada em 1960 pelo psicólogo suíço Jean Piaget, em uma pesquisa sobre a internalização de regras morais por crianças. Seus achados 


\section{VOZES $_{\text {\&IÁLORO }}^{\mid}$}

Itajaí, v. 18, n. 02, jul/dez 2019

concluíram que os processos cognitivos dos agentes obedeciam a diferentes etapas na codificação de normas. No estágio mais avançado, sujeitos são autônomos o suficiente para contestar a imposição de regras e imaginar outros valores, por exemplo.

A partir das contribuições de Piaget, e com base em testes realizados em estudantes homens da Universidade de Harvard, o psicólogo estadunidense Lawrence Kohlberg (1992) propôs seis estágios que refletem progressiva e linearmente um grau de raciocínio ético. Refinado posteriormente, o modelo passa a ser concebido de modo menos estanque: sujeitos podem regredir em seus estágios e recorrer a raciocínios éticos menos complexos, mesmo que já tenham demonstrado um alto grau de argumentação. Nessa proposta, entende-se que pensamentos são efetuados por meio de esquemas, ou seja, interações sociais prévias que processam informações na resolução de dilemas éticos.

As seis categorias de Kohlberg (1992), portanto, são transformadas em três esquemas. O esquema dos interesses pessoais substitui o primeiro estágio, préconvencional. Nessa etapa, agentes compreendem que regras são desenvolvidas por figuras autoritárias; violá-las significaria receber alguma punição. $\mathrm{O}$ estágio convencional passa a ser, na teoria dos esquemas, a manutenção de normas. Obedece-se a regras porque o sujeito compreende que elas servem à ordem social, podendo ser modificadas apenas se todos concordarem com as alterações. Por fim, o estágio pós-convencional permanece com o mesmo nome na teoria dos esquemas. Entende que regras e leis são respeitadas apenas se possuírem um apelo ético universal, sem favorecer determinados grupos. Sujeitos que internalizam essa compreensão estão dispostos a desafiar normas sociais, deixando seus interesses de lado.

Uma das críticas feitas a Kohlberg questiona a natureza estritamente lógica e racional das decisões morais. Para Carol Gilligan (1993), a emoção também desempenha um papel relevante na resolução de dilemas. Ao incluir mulheres em suas entrevistas, a psicóloga observa que conflitos éticos não são resolvidos apenas por princípios gerais, mas também pelo senso de responsabilidade que agentes têm uns com os outros. Gilligan (1993) articula uma ética feminista do cuidado, em complemento à pesquisa do autor suíço, para destacar o aspecto relacional dos sujeitos nas suas tomadas de decisão ${ }^{5}$.

Os estudos em jornalismo que recorrem à área do desenvolvimento moral utilizam, principalmente, as suas contribuições metodológicas para compreender dilemas jornalísticos. Resultado de extensas entrevistas em profundidade, o trabalho de Kohlberg gerou obras com mais de 800 páginas, catalogando dados de cada estágio moral dos participantes. Para facilitar o mensuramento dos julgamentos, James Rest, um dos alunos do psicólogo, desenvolveu com seus colegas o instrumento Defining Issues Test (DIT). Originalmente feito para profissões com dilemas morais complexos, como as da área da

\footnotetext{
${ }^{5}$ Cabe salientar que Gilligan também recebe críticas de autoras feministas porque sua análise incorre em certo essencialismo, sugerindo que mulheres carregam consigo a característica inata do cuidado (ESS, 2009).
} 


\section{VOZES $_{\text {\&IÁLORO }}^{\mid}$}

Itajaí, v. 18, n. 02, jul/dez 2019

saúde, o DIT passou a ser utilizado desde a década de 1970 em estudos de diversas áreas para mensurar tomadas de decisão em situações incertas. Ao total, mais de 400 estudos em 40 países já foram feitos com o DIT, o que comprovaria a sua validade, segundo Coleman e Wilkins (2009).

No teste, são apresentados seis dilemas éticos fictícios e 12 afirmações argumentativas. Cada opção corresponde a algum estágio moral de Kohlberg, do pré ao pós-convencional. Os participantes justificam as quatro frases que consideram de maior importância na sua tomada de decisão e, a partir dessas respostas, é realizado um cálculo que toma como base o nível ético mais alto (pós), formando um score $\mathrm{P}$ de valor agregado. Rest et al (1999) adicionaram propositalmente afirmações vagas, que parecem apelar à moral desejada pelo pesquisador. Quando os sujeitos conferem alto grau de importância a elas, o resultado do DIT é descartado por sugerir que os respondentes tentam parecer éticos. O mesmo acontece quando "pouca importância” é assinalada diversas vezes: entende-se que há uma automatização nas respostas, apenas para finalizar rapidamente o teste.

Com a estabilidade nos resultados do DIT aplicado a diversas profissões durante 30 anos, Rest e seus colegas criaram uma segunda versão (DIT-2), que incorpora dois novos dilemas fictícios à escolha do pesquisador. A ideia é contribuir para que estudos insiram questões éticas específicas de sua área.

É com base no DIT que são realizadas parte das pesquisas sobre psicologia moral aplicada ao jornalismo. Um dos primeiros e mais abrangentes estudos é o de Wilkins e Coleman (2005), com uma amostra de 249 jornalistas dos Estados Unidos. Profissionais pontuaram um score de 48.68, semelhante ao estudo The cognitive moral development of journalists, de Thomas Westbrook, o primeiro a utilizar o DIT com jornalistas, em 1995. Em menor escala, essa pesquisa contou com 66 jornalistas e registrou score de 48.1.

Em comparação com outras pesquisas de DIT já realizadas, Wilkins e Coleman (2005) estimam que jornalistas são o quarto grupo profissional com maior desenvolvimento de raciocínio ético, atrás de filósofos, médicos e estudantes de medicina. Estão à frente de dentistas, advogados, enfermeiros, relações públicas, publicitários, entre outros. Mas o que explica esse alto número nos julgamentos morais de jornalistas? Quais são as implicações disso?

Além do DIT, as pesquisadoras também realizaram um questionário geral com os participantes para aferir dados diversos. A partir dele, algumas correlações foram possíveis. Observou-se, por exemplo, que respondentes identificados com fundamentalismos religiosos tiveram baixo score de raciocínio ético. Segundo Wilkins e Coleman (2005), estudos com outros grupos profissionais também encontraram essa correlação, o que pode ser explicado pela intolerância a visões contrárias prescritas pelas normas morais de ideologias fundamentalistas, mantendo estagnados os esquemas cognitivos. 


\section{VOZES $_{\text {\&IÁLORO }}^{\mid}$}

Itajaí, v. 18, n. 02, jul/dez 2019

Jornalistas inclinados a posições políticas liberais pontuaram um alto nível de raciocínio moral no DIT das pesquisadoras. O gênero, por sua vez, não produziu diferenças significativas - mulheres obtiveram um score discretamente maior. Raça, no entanto, foi um fator relevante na resolução de dilemas morais. Quando pessoas negras eram utilizadas como protagonistas de dilemas morais específicos do jornalismo, o nível de raciocínio moral tendia a ser mais baixo, o que pode ser interpretado como o acionamento de estereótipos vinculados a ideologias racistas, sejam elas conscientes ou não.

O tipo de jornalismo exercido (em rádio ou impresso) não foi relevante, embora repórteres investigativos tenham pontuado um score mais alto. Segundo as autoras, esse gênero enfrenta questões éticas com mais frequência do que outras práticas jornalísticas, que lidam com dilemas morais de forma mais episódica. Nesse sentido, ao "exercitarem" suas reflexões, pressupõe-se que jornalistas investigativos ganham experiência, o que coaduna com a teoria dos esquemas que citamos anteriormente. Estes profissionais, portanto, guardam modelos mentais de eventos que já resolveram, o que auxilia nas suas tomadas de decisão frente a novos problemas.

Um fator expõe a importância do contexto organizacional nas tomadas de decisão: para Wilkins e Coleman (2005), o poder de escolha é uma variável relevante - quanto mais o jornalista dispõe dela (seja na escolha para cobrir a notícia que deseja ou praticar o jornalismo que gostaria) mais alto é o score P. É sintonizado com a compreensão contemporânea de desenvolvimento, entendido como um "conjunto complexo de interações dinâmicas do ser humano, que vive em um ambiente externo igualmente dinamizado" (WILKINS; COLEMAN, 2005, p. 3). O desenvolvimento moral, por sua vez, é definido pela noção de que "o modo como as pessoas pensam sobre questões éticas muda conforme o tempo, em parte devido ao desenvolvimento de outras psiques do indivíduo (como o intelecto) e em parte como resposta aos ambientes sociais e culturais em que as pessoas se encontram" (op. cit).

Treze anos depois, jornalistas diminuíram sua pontuação no teste DIT, segundo uma nova pesquisa com 171 profissionais estadunidenses (FERRUCCI; TANDOC JR.; SCHAUSTER, 2019). O decréscimo no score, de 48.68, em 2004, para 41.61., em 2017, é explicado pelos autores como um sintoma de desprofissionalização do jornalismo e possível afrouxamento das normas éticas na identidade do jornalista.

Além dessa atualização, outros estudos desdobraram as pesquisas de Wilkins e Coleman (2005) ao longo da década. Correa (2009), por exemplo, examina se a classe social dos sujeitos das notícias influencia no raciocínio ético de jornalistas. Sua hipótese é a de que profissionais apresentam níveis baixos de desenvolvimento moral quando os sujeitos das histórias não são de classes médias e altas. O que sustenta essa ideia é a teoria psicológica da identificação social: membros de grupos tendem a demonstrar sentimentos positivos para sujeitos que eles consideram familiares. Nesse sentido, os jornalistas chilenos pesquisados pela autora, que são, em termos gerais, sujeitos homens, brancos e de classe 


\section{VOZES $_{\text {\&IÁLORO }}^{\mid}$}

Itajaí, v. 18, n. 02, jul/dez 2019

média, tendem a se envolver com seus semelhantes. A identificação social associa elementos emotivos, como a empatia, e cognitivos, a exemplo da ideia de compartilhar o mesmo comportamento de outra pessoa por ser parte de um grupo.

Utilizando uma metodologia derivada do DIT, o Journalists' Ethical Reasoning Instrument, Correa (2009) apresentou dilemas morais específicos da profissão (cobertura sobre suicídio, violência doméstica, abuso sexual e de drogas) para 97 participantes. Jornalistas deveriam decidir se publicavam as histórias ou não depois que o protagonista delas mudou de ideia e pediu para que elas não viessem a público. Em dois dos dilemas, os sujeitos eram de classe média; nos outros, de classe baixa. Além disso, ainda foi aplicado um questionário com os respondentes, para que eles aferissem o quão envolvidos se sentiram com a fonte principal da história.

Correa (2009) concluiu que a classe dos sujeitos afeta o raciocínio moral dos jornalistas indiretamente: ela, por si só, não é correlacionada ao baixo nível de desenvolvimento. Isto ocorre apenas quando há também um baixo envolvimento dos profissionais com os sujeitos da notícia. Portanto, os efeitos de estereótipos baseados em classes sociais são moderados por mecanismos psicológicos, como a empatia e a aproximação do profissional com a fonte. A teoria da identificação social, por sua vez, não oferece explicações satisfatórias para dilemas morais.

Uma vez que o racismo é fator que interfere no julgamento moral de jornalistas, Coleman (2011) questiona se profissionais que fazem parte de minorias desenvolvem um raciocínio menos estereotipado sobre questões raciais. Assim como indicam os resultados de Correa (2009), Coleman (2011) sugere que a empatia pode estar ligada à redução de estereótipos, por ser um fator psicológico que impulsiona o pensamento moral para a ação. Seria plausível, portanto, que grupos minoritários que lutam contra a discriminação desenvolvessem uma resposta empática e, por consequência, um raciocínio moral mais elevado com membros de outras minorias.

Participaram 224 jornalistas asiáticos, negros e hispânicos, que foram apresentados a dilemas jornalísticos sobre questões sociais envolvendo fontes de minorias. Nos mesmos moldes de Correa (2009), o estudo também trouxe quatro questões específicas sobre a empatia que sentiram pelos protagonistas das histórias fictícias.

Novamente, os resultados contrariaram a teoria da identificação social, que atribui características positivas a grupos semelhantes. Na amostra pesquisada, percebeu-se que jornalistas de minorias tratam igualmente todas as raças em relação às decisões morais, sem demonstrar preferência pela sua própria etnia ou transparecer um viés negativo em relação a outra. A empatia foi correlacionada com um alto nível de julgamento moral de asiáticos e negros, mas não no caso de hispânicos. Coleman (2011) não atribui nenhuma explicação específica para esse resultado.

De forma geral, o estudo revela que dois grupos de minorias jornalísticas demonstram aperfeiçoar seu julgamento moral quando sentem simpatia e compaixão pelas 


\section{VOZES $_{\text {\&IÁLOGO }}^{\mid}$}

Itajaí, v. 18, n. 02, jul/dez 2019

pessoas em seus dilemas, e imaginam estar no lugar delas. Para qualificar as tomadas de decisão no jornalismo, a pesquisadora sugere que é útil mirar nas emoções dos profissionais e, em especial, no valor da empatia.

Outro desdobramento é a pesquisa de Lee, Coleman e Molyneux (2016), que toca em uma questão-chave: se jornalistas estão entre os profissionais com alto grau de raciocínio ético, por que ainda se comete erros no jornalismo? Qual é o gap que existe entre pensar e agir eticamente? Sugerir que os sujeitos operam em altos níveis de raciocínio moral não significa concluir que eles agem de forma mais ou menos ética nos mesmos dilemas, dizem os autores.

Essa é uma preocupação clássica da psicologia. Nas pesquisas de comportamento, normas sociais têm um impacto significativo para essa lacuna. Entende-se que elas são a percepção dos sujeitos sobre a pressão de desempenhar um comportamento específico. Há dois grupos de normas sociais: as injuntivas (a percepção que temos sobre como outras pessoas, particularmente aquelas que consideramos importantes, acham que devemos agir) e as descritivas (a percepção que temos sobre como essas outras pessoas agem).

Essa distinção modula, em alguma medida, o próprio comportamento humano, embora as categorias nem sempre sejam completamente separáveis. Para Lee, Coleman e Molyneux (2016), normas injuntivas desestimulam comportamentos por priorizarem o que outros considerariam reprováveis (uma placa de "não pise na grama", por exemplo). As descritivas seriam o contrário: se outras pessoas se comportam de tal maneira, haveria um estímulo (“muitas pessoas já pisaram na grama e a estragaram”), o que pode ser útil na promoção de boas práticas.

Utilizando essas duas ideias como base, as autoras partem da hipótese de que normas injuntivas indicam comportamentos antiéticos no jornalismo, ao passo que normas descritivas sugerem comportamentos éticos. A análise contou com uma amostra de 45 jornalistas estadunidenses que trabalhavam em 33 redações. Foi aplicado um survey com seis comportamentos jornalísticos - três éticos ("reportar diversas perspectivas em uma história”, por exemplo), três antiéticos (“publicar releases sem editá-los”). Perguntou-se aos participantes quando foi a última vez que eles se viram em situações como aquelas. Em seguida, para aferir a norma injuntiva, marcaram em uma escala Likert de 7 pontos o quanto aquele comportamento era aprovado ou reprovado de acordo com 1) seu editor; 2) seus colegas da mesma instituição; 3) seus colegas de outra instituição dentro da mesma indústria; 4) seus colegas de outras indústrias de notícia (para um jornalista impresso seriam colegas de rádio, por exemplo). Para a norma descritiva, utilizou-se da mesma escala e fatores, mas para responder o quanto colegas desempenhavam, de fato, o comportamento ético ou antiético.

Os resultados das pesquisadoras encontraram correlação em dois dos três comportamentos antiéticos referentes às normas injuntivas. Ou seja, jornalistas efetuariam essas práticas se soubessem que outros profissionais aprovariam as atitudes. Normas 


\section{VOZES $_{\text {\&IÁLORO }}^{\mid}$}

Itajaí, v. 18, n. 02, jul/dez 2019

descritivas, que indicam comportamentos éticos, foram sustentadas pelos três dilemas analisados no estudo. Quando profissionais pensam que outros jornalistas estão engajados nestes comportamentos, tendem a aderi-los.

Nesse sentido, o estudo sugere que a atuação positiva de jornalistas no estágio pósconvencional se deve antes por uma consciência ética (processada e internalizada principalmente por bons exemplos) do que pela expectativa de seus pares. Normas sociais têm mais peso para a validação de práticas antiéticas de jornalistas.

A partir dessas conclusões, Lee, Coleman e Molyneux (2016) lançam pistas sobre como normas descritivas podem ser reforçadas para qualificar o raciocínio de jornalistas frente a julgamentos morais. Algumas ações a serem tomadas incluem discutir e compartilhar, dentro das redações, exemplos de comportamentos éticos de repórteres, a fim de mimetizar seu comportamento. A observação de boas práticas, como o estudo sugere, auxilia no reconhecimento de escolhas éticas complexas e "exercita" a tomada de decisão destes profissionais. Essa visada tem seu alicerce na ética das virtudes, que se preocupa com o desenvolvimento do caráter. Pensar um jornalismo virtuoso, portanto, pode ser a chave para qualificar julgamentos morais.

\section{Phrônesis: sabedoria prática nas tomadas de decisão}

Se as normas descritivas reconhecem que jornalistas tendem a internalizar e eventualmente mimetizar, em alguma medida, comportamentos éticos observados em seus pares, a ética das virtudes fornece terreno teórico que sustenta as tomadas de decisão no jornalismo orientando-as pela via do caráter, e não das regras. É uma perspectiva diferente da deontologia, por exemplo, que formula princípios morais e materializa-os em mecanismos externos, como códigos profissionais e regulamentações. Subjaz a essa compreensão que a ação dos agentes ocorre em obediência às normas.

A doutrina das virtudes é fundamentada por Aristóteles e foca nas práticas morais dos sujeitos exercidas pelo seu caráter, com o objetivo de atingir a excelência. Aliar a psicologia moral à ética das virtudes pode ser o sustento teórico necessário para aprofundar fatores que atravessam julgamentos, como motivações, intenções e emoções, culminando na descrição de um caráter profissional virtuoso.

Uma abordagem virtuosa do jornalismo está preocupada com boas práticas que possam servir de modelo (CHRISTOFOLETTI, 2012), algo semelhante às normas descritivas tratadas anteriormente (LEE; COLEMAN; MOLYNEUX, 2016). Pesquisadores que observam a ética jornalística sob esse prisma (ADAM; CRAFT; COHEN, 2004; BORDEN, 2007; HEINO, 2013; PLAISANCE, 2014; QUINN, 2018) enfatizam antes o caráter dos agentes do que a obediência a regras morais. Substitui-se a pergunta "o que deve ser feito?" para “o que é melhor para a sociedade?” (COULDRY, 2013), com foco na finalidade (télos) das ações. Diz-se, portanto, que a doutrina das virtudes é teleológica. 


\section{VOZES $_{\text {\&IÁLORO }}^{\mid}$}

Itajaí, v. 18, n. 02, jul/dez 2019

Há três conceitos centrais na ética aristotélica: arête (virtudes), phrônesis (sabedoria prática) e eudaimonia (florescimento humano). A primeira delas, que dá nome à doutrina do filósofo grego, refere-se às disposições necessárias para o agir moral. Adquirir virtudes pressupõe um grau de excelência do caráter e uma compreensão geral sobre moralidades. Quinn (2018) utiliza a virtude da verdade como exemplo: quem está comprometido a contar o que é verdadeiro, o faz porque entende que há algo intrinsecamente bom no ato. Está, portanto, internalizado no seu caráter e psiquê - não se conta a verdade porque é “correto”, como preconizaria a deontologia, mas porque o agente entende que há uma motivação moral por trás da ação. Aquilo que é certo deriva de uma noção mais geral daquilo que é o bem.

Phrônesis significa sabedoria prática: é o conhecimento moral necessário para agir de acordo com a virtude. Ou seja, se possuir alguma dessas disposições é condição para ser virtuoso, é preciso também saber utilizá-las com prudência. Esse conhecimento é adquirido através de experiências contínuas e de modelos, ligando virtudes à educação formal e também às normas descritivas.

Na teoria ética de Aristóteles, a phrônesis é classificada como uma virtude intelectual que envolve deliberações baseadas em valores, preocupada com julgamentos práticos (KINSELLA; PITMAN, 2012). Ela distingue-se de outras duas do mesmo tipo episteme e a techne. A primeira é o conhecimento científico, universal e invariável que origina a epistemologia. Já a segunda refere-se ao conhecimento pragmático, variável e dependente de contextos, orientada para uma racionalidade instrumental. Dá origem a termos como técnica e tecnologia.

Eudaimonia, por sua vez, é o florescimento humano do agente. Diz respeito à finalidade das ações, àquilo que orienta a prática virtuosa. Aristóteles propõe uma teoria ética voltada ao bem comum; o ato de florescer, portanto, não é individual. Pode ser resumido na ideia de "viver bem em conjunto", sendo que eudaimonia é um conceito que não se reduz à felicidade, mas a autorrealização do sujeito ${ }^{6}$. Esse fundamento no comunitarianismo origina correntes éticas como o cuidado, discutido anteriormente na filosofia feminista de Gilligan (1993), que coloca a agência moral em uma perspectiva relacional.

Podemos observar que os três elementos coexistem: uma ação moral virtuosa necessidade de disposições - as virtudes - orientadas para uma finalidade - o florescimento. Nas tomadas de decisões frente a dilemas, agentes se valem de um saber prático, a phrônesis. A nosso ver, este parece ser um dos elementos-chave para explicar o desenvolvimento moral no jornalismo.

\footnotetext{
${ }^{6}$ Críticos à teoria ética de Aristóteles consideram sua ideia de florescimento humano demasiadamente vaga. Filósofos neoaristotélicos que retomam a doutrina das virtudes a partir da década de 1970 e 1980 buscam explicações mais substanciais para a ideia de eudaimonaia, sendo Alasdair Maclntyre um de seus principais representantes, em Depois da virtude (2001).
} 


\section{VOZES $_{\text {\&IÁLORO }}^{\mid}$}

Itajaí, v. 18, n. 02, jul/dez 2019

Uma vez que julgamentos morais pressupõem tomadas de decisão, vamos nos deter no conceito de phrônesis, ou seja, no conhecimento necessário para atingir determinados fins. Como se dá a construção dessa reflexão virtuosa? Kinsella (2012) lembra que pensamentos não são práticas apenas individuais, mas sustentadas por outro pensamento de fundo, coletivo, semelhante à compreensão cognitiva de que partilhamos um terreno comum pré-organizado e esquemático (VAN DIJK, 1990). A autora recorre a pesquisas da fenomenologia e sintetiza um continuum na operação dos processos reflexivos, que ocorre de forma dinâmica e interativa. A phrônesis, portanto, instaura uma reflexão intencional (considerações sobre crenças), incorporada (conhecimento revelado na ação), sensível (que intui emoções) e de reflexividade (o discernimento das condições sociais acerca do próprio conhecimento). Nesse sentido, o sujeito orientado ao conhecimento prático da phrônesis está ciente de que a reflexão transpassa características individuais, atento ao "papel do poder, do discurso e da intersubjetividade na construção de 'versões da realidade' na prática, e consciente do imperativo da reflexão atenta e do diálogo" (KINSELLA, 2012, p. 47).

A reflexão está implicada na prática profissional através de julgamentos e ações. Phrônesis é um conceito particularmente relevante ao jornalismo por se tratar de uma profissão que vivencia situações indeterminadas, lida com acontecimentos complexos e precisa tomar decisões a todo instante (DONSBACH, 2004). Contudo, o que qualificaria um julgamento como "phronetico"? Para caracterizá-lo, Kinsella (2012) contribui com três critérios específicos - que não são o fundamento da phrônesis em um sentido normativo, como alerta, mas considerações que podem guiar agentes morais dispostos a tomar decisões com base na sabedoria prática.

Dois dos critérios são o imperativo ético e o potencial de transformação. No primeiro caso, Kinsella (2012) expõe a centralidade da moral no conhecimento das profissões; no segundo, incorpora a necessidade de que decisões não devem obedecer apenas a pragmatismos pessoais, mas à possibilidade de emancipação e engajamento movidos pelo interesse em justiça social.

Contudo, o critério que nos parece mais relevante para caracterizar a phrônesis é a intersubjetividade dialógica (KINSELLA, 2012). Trata-se de reconhecer que a consciência e a reflexão não são apenas individuais, mas processos de natureza social e coletiva. Portanto, interpretações de dilemas morais abrangem uma perspectiva relacional. Kinsella (op. cit.) menciona a ética do cuidado como um exemplo que reconhece a natureza dialógica das decisões, pois pressupõe que também guardamos uma responsabilidade perante os outros. Assim, a intersubjetividade implica significados negociados dentro de um conjunto de práticas discursivas. A phrônesis, ao considerar essa natureza, estende sua interpretação para a realidade dos outros, aberta às possibilidades dialógicas implicadas nesse reconhecimento. 


\section{VOZES $_{\text {\&DÁLORO }}^{\mid}$}

Itajaí, v. 18, n. 02, jul/dez 2019

A ênfase na perspectiva relacional nos faz considerar que um dos elementos centrais da phrônesis é a empatia. Essa hipótese foi reforçada por alguns estudos anteriores que mencionamos. Na sua teoria dos estágios, Kohlberg já considerava que a chave para passar de uma etapa a outra era o aprendizado de ler situações do ponto de vista de outras pessoas (COLEMAN; WILKINS, 2009). Correa (2009) sugeriu que o envolvimento de jornalistas com os sujeitos das notícias é o que pode minimizar seus preconceitos com classes sociais e complexificar o pensamento moral. Coleman (2011) também correlacionou o alto nível de julgamento com a empatia e a compaixão que pessoas sentem pelos sujeitos, quando imaginam como é estar no lugar deles. Para Lippmann (2009, p. 120), "é somente quando temos o hábito de reconhecer nossas opiniões como uma experiência parcial vista através de nossos estereótipos que nos tornamos verdadeiramente tolerantes de um oponente", o que destaca a natureza social dos julgamentos morais e a conexão com o outro. A pesquisa de fôlego realizada por Wilkins e Coleman (2005) correlaciona altos níveis de raciocínio ético com jornalistas investigativos, como discutimos, e também com jornalistas cívicos, cujas práticas são fundamentadas pelo comunitarianismo e pela ética do cuidado, como já demonstraram outras pesquisas (STEINER; OKRUSCH, 2006; URE; PARSELIS, 2010; WILKINS, 2010; PAUL, 2017).

\section{Considerações finais}

Em síntese, ao enfatizar que julgamentos morais decorrem principalmente do caráter, e não da obediência a princípios morais, a ética das virtudes sublinha que o agente adquire conhecimento moral e experiência por meio de contínuas ações virtuosas. Assim, consegue complexificar e adicionar mais variáveis em suas decisões, numa perspectiva relacional. Virtudes, por sua vez, são internalizadas pela prática consciente do agente e também pela influência de "modelos virtuosos", como familiares, amigos e pares (QUINN, 2018). No caso do jornalismo, a validação social dos colegas jornalistas atravessa significativamente suas decisões morais (DONSBACH, 2005). Da mesma forma, o estudo de Lee, Coleman e Molyneux (2016) pontua que normas descritivas estimulam comportamentos éticos positivos. Logo, quando jornalistas observam que seus pares compartilham e discutem boas práticas no jornalismo, estes tendem a mimetizá-los. Em uma das correlações de resultados no teste de DIT mais recente até então, Ferrucci, Tandoc Jr. e Schauster (2019) concluem que a socialização de valores morais ocorre com mais frequência em redações menores, onde o acesso a jornalistas que servem como "modelos éticos" é facilitado.

O estímulo para a phrônesis nos processos de decisão no jornalismo perpassa três instâncias. A primeira delas é a discussão aberta sobre ética nas redações, o que inclui a transparência dos processos de apuração e o compartilhamento de experiências. A segunda diz respeito à educação formal nas universidades. Quinn (2018) critica o modelo curricular estadunidense, em especial a dimensão ética, e o considera falho na preparação de 


\section{VOZES $_{\text {\&IÁLORO }}^{\mid}$}

Itajaí, v. 18, n. 02, jul/dez 2019

profissionais virtuosos. O autor ainda cita que programas de treinamento raramente aprofundam questões morais, e discursos sobre ética tendem a ser vistos como mera retórica. Por último, não basta termos um agente virtuoso para praticar ações virtuosas. No jornalismo, o poder de decisão é correlacionado ao desenvolvimento moral (WILKINS; COLEMAN, 2005), e está ligado a autonomia dos agentes. Logo, a phrônesis também é atravessada pela natureza institucional das organizações - seu alinhamento político, concentração de propriedade, entre outros fatores que podem contrariar interesses do indivíduo.

Concluímos, portanto, que a phrônesis fornece elementos para o aperfeiçoamento dos julgamentos realizados por jornalistas. Está estreitamente vinculada à ideia de empatia, chave moral para complexificar a dimensão ética da prática jornalística. Nesse sentido, o aporte teórico da psicologia cognitiva enfatiza a natureza social na construção do conhecimento, além dos seus componentes psicológicos. Do mesmo modo, a doutrina das virtudes fornece sustento teórico para compreendermos a ética jornalística para além de regramentos morais que normatizam e podem engessar práticas profissionais. Reiteramos, por fim, que uma abordagem multidisciplinar é necessária para compreender o campo específico da ética jornalística, especialmente nos processos de deliberação moral, para que análises micro não se tornem individualizantes, mas conectem-se à totalidade dos fenômenos.

\section{Referências}

ADAM, S.; CRAFT, S.; COHEN, E. Three essays on journalism and virtue. Journal of Mass Media Ethics, v. 19, n. 2, pp. 247-275, 2004.

ARISTÓTELES. Nicomachean ethics. Tradução de Roger Crisp. Cambridge University Press: Cambridge, 2000.

BORDEN, S. Journalism as practice: MacIntyre, Virtue Ethics and the Press. Hampshire: Ashgate Publishing Limited, 2007.

CHRISTOFOLETTI, R. Ética no jornalismo. São Paulo: Contexto, 2008.

CHRISTOFOLETTI, R. Para uma abordagem virtuosa do jornalismo. Em Questão, v. 18, p. 93-107, 2012.

COLEMAN, R.; WILKINS, L. Moral development: a psychological approach to understanding ethical judgmenet. In: WILKINS, L.; CHRISTIANS, C (eds). The handbook of mass media ethics. New York: Routdlege, 2009.

COLEMAN, R. The moral judgement of minority journalists: evidence from asian american, black, and hispanic professional journalists. Mass Comunication and Society, v. 14, n. 5, p. 578-599, 2011. 


\section{VOZES $_{\text {\&DÁLORO }}^{\mid}$}

Itajaí, v. 18, n. 02, jul/dez 2019

CORREA, T. Does class matter? The effect of social class on journalists' ethical decision making. Journalism \& Mass Communication Quarterly, v. 86, n. 3, p. 654-672, 2009.

COULDRY, N. Why media ethics still matters? In: WARD, Stephen (ed.). Global media ethics: problems and perspectives. Chichester: Wiley-Blackwell, 2013.

DONSBACH, W. Psychology of news decisions: factors behind journalists' professional behavior. Journalism, v. 5, n. 2, p. 131-157, 2004.

ESS, C. Digital media ethics. Polity Press: Cambridge, 2009.

FERRUCCI, P.; TANDOC JR., E.; SCHAUSTER, E. Journalists primed: how professional identity affects moral decision making. Journalism Practice, 2019.

FISHMAN, M. Manufacturing the News. Austin: University of Texas Press, 1990.

GANS, H. Deciding what is news. Evanston, IL: Northwestern University Press, 2004.

GILLIGAN, C. In a different voice: psychological theory and women's development. Harvard University Press: Cambridge, 1993.

GUERRA, J. A 'desreificação' como fenômeno ético: uma releitura da tese de Berger e Luckmann sobre a construção social da realidade. Tomo, São Cristóvão, n. 4, p. 29-53, 2001.

HEINO, K. The virtuous journalist, an updated view. A study in the ethics of journalism. Tese (Doutorado em Filosofia) - Universidade de Turku, Finlândia, 2012.

KINSELLA, E. Practitioner reflection and judgement as phronesis: a continuum of reflection and consideration for phronetic judgement. In: KINSELLA, Elizabeth; PITMAN, Allan (eds). Phronesis as professional knowledge: practical wisdom in the professions. Rotterdam: Sense Publishers, 2012.

KINSELLA, E; PITMAN, A. Engaging phronesis in professional practice and education. In: KINSELLA, Elizabeth; PITMAN, Allan (eds). Phronesis as professional knowledge: practical wisdom in the professions. Rotterdam: Sense Publishers, 2012.

KOHLBERG, L. Psicologia del desarrollo moral. Bilbao: Editorial Desclée de Brower, 1992.

LEE, A.; COLEMAN, R.; MOLYNEUX, L. From thinking to doing: effects of different social norms on ethical behavior in journalism. Journal of Media Ethics, v. 31, n. 2, p. 72 $85,2016$.

LIPPMANN, W. A opinião pública. Petrópolis/RJ: Vozes, 2009.

LORENZO, J. La ética periodística como ética aplicada. Revista de Filosofia, n. 44, 2011. 


\section{VOZES $_{\text {\&IÁLORO }}^{\mid}$}

Itajaí, v. 18, n. 02, jul/dez 2019

QUINN, A. Virtue ethics and professional journalism. California: Springer, 2018.

MACINTYRE, A. Depois da virtude: um estudo em teoria moral. Bauru: Edusc, 2001.

PAUL, D. Valores morais em atos de jornalismo: reflexões sobre uma ética para nãojornalistas. Dissertação de mestrado. Florianópolis: UFSC, 2017.

PLAISANCE, P. Virtue in media: the moral psychology of U.S. exemplars in News and Public Relations. Journalism \& Mass Communication Quarterly, v. 91, n. 2, pp. 308-325, 2014.

REST, J.; NARVAEZ, D. BEBEAU, M.; THOMA, S. Postconventional moral thinking: a Neo-Kohlbergian approach. Lawrence Erlbaum Associates: New Jersey, 1999.

SCHMITZ, A Os graus de autonomia do jornalista brasileiro: lacunas entre ideais, percepções e práticas profissionais efetivas nos jornais Folha de S. Paulo, O Estado de $\mathrm{S}$. Paulo, O Globo e Zero Hora. Tese (Doutorado em Sociologia Política) - Universidade Federal de Santa Catarina, Florianópolis, 2018.

STEINER, L.; OKRUSCH, C. Care as a virtue for journalists. Journal of Mass Media Ethics, v. 21, n. 2\&3, p. 102-122, 2006.

STOCKING, SH.; GROSS, P. How do journalists think? A proposal for the study of cognitive bias in newsmaking. Bloomington: ERIC, 1999.

TUCHMAN, G. Making news. New York: The Free Press, 1978.

URE, M.; PARSELIS, M. Una ética autorregulada para el periodismo ciudadano. Global Media Journal México, v. 7, n. 13, p. 19-32, 2010.

VAN DIJK, T. La noticia como discurso: comprensión, estructura y producción de la información. Barcelona: Ediciones Paidós, 1990.

VAN DIJK, T. Ideology: a multidisciplinary approach. London: SAGE Publications, 1998.

VAN DIJK, T. Notícias e conhecimento. Estudos em Jornalismo e Mídia, v. 2, no 2, p. 1329, 2005.

WILKINS, L.; COLEMAN, R. The moral media: how journalists reason about ethics. Mahwah: Lawrence Erlbaum, 2005.

WILKINS, L. Connecting care and duty: how neuroscience and feminist ethics can contribute to understanding professional moral development. In: WARD, Stephen; WASSERMAN, Herman (eds.). Media ethics beyond borders: a global perspective. New York/London: Routledge, 2010. 